\title{
Determining Which Delivery Styles Are Best Suited For Instructing In The Distance Learning Environment
}

\author{
James T. Schultz, Embry-Riddle Aeronautical University \\ Marian C. Schultz, University of West Florida \\ Thomas Henkel, Embry-Riddle Aeronautical University
}

\begin{abstract}
The purpose of this study was to ascertain if there is a specific style of teaching which is better suited for the distance learning (virtual) environment, as opposed to the traditional classroom environment. Numerous studies have shown that individuals have different delivery styles in the classroom. The study utilized instructor delivery styles and faculty perceptions of distance learning programs to develop an instrument which identifies the style that would be more successful in the distance learning environment. The study employed an author developed instrument, which included a derivative of the Kolb Learning Style Inventory (LSI) instrument, to determine the teaching style of the instructor. Results of the study concluded that while there will always be exceptions, the instrument developed in the study will provide an indication of which instructors are better suited for the virtual environment.
\end{abstract}

\section{INTRODUCTION}

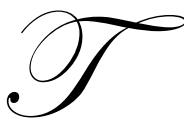

oday's dynamic educational milieu has transitioned from the traditional educational delivery method of a professor standing in front a classroom filled with students to one which has been augmented, and in some cases supplanted, by various on-line, distance learning delivery methodologies. Although some faculty integrate different teaching approaches and styles in the classroom, some achieve a high degree of success in distance learning courses, as measured by both their personal gratification and student evaluations. Similarly, there are faculty who discover that teaching on-line can prove to be a very disappointing and unrewarding experience, for both their students and themselves.

Although educational delivery methodologies have been in a constant state of transition in recent years, the concept of distance education is not new. The University of Chicago offered the first major correspondence program in America in the late 1800s where the instructor and students were not in the same location (Sherry, 1996). Today, technology has all but supplanted the correspondence format, and students can now earn a degree by sitting at a computer terminal with an internet connection.

\section{ON-LINE INSTRUCTION}

Online instruction varies from the classroom instruction. A reputation as a great classroom instructor does not necessarily equate or translate into a great online instructor. To be effective, an instructor needs to possess an appropriate teaching style and demeanor that encompasses the pedagogical, social, managerial, and technical skills that are necessary to meet the needs of the students. The rise in popularity of distance learning programs has brought about a concern for the process of evaluating the effectiveness of on-line instructors. The role of online instructor requires more than just knowledge of the subject area. "...most professors do not fully appreciate and understand the complexities of online teaching until they have taught their first course..." (Kearsley \& Blomeyer, 2004, p. 5). 
According to Berge (1998), while the use of technology is important in virtual instruction, a vital consideration is positioned in the pedagogical arena. This area should be approached in a non-authoritarian style, especially with adult learners. Facilitating or guiding the students in discussions which are intended to complement the student's understanding of the subject is one of the most important goals of an on-line instructor.

Many believe that instruction via the computer can never replace the physical presence of a talented instructor (Bricken, 1991). When instructors teach a virtual class they lose the physical presence that they often take for granted in a traditional classroom. A classroom can be compared to a play with the instructor as the lead actor. The instructor must deliver a script to an audience while incorporating non-verbal communications and emotions resulting in continuous adjustments in the classroom. The use of experiential or hands-on course work can be closely monitored allowing debriefing to be adapted to fit the students' diverse comprehension and interest levels. However, in a virtual class, the students become the driving force for their own education. The instructor surrenders the focal role and assumes the role of the facilitator. This new role opens the door to creativity and student self reliance, while eliminating the constraints of a conventional classroom setting. The role of the distance learning instructor is critical as they become a facilitator of learning rather than a communicator of a fixed body of information (Perraton, 1988; as cited in Sherry, 1996).

According to Reingold (1998) teaching students at a distance is much more demanding than classroom teaching and requires substantially more meticulous planning. Because distance instruction is relatively new in terms of computer technology, a system has not as yet been developed to determine the type of instructor who would be effective in the virtual arena. He further identifies five areas in which instructors need to concentrate when developing their approach: control, quality, capability, creativity and scope.

A study by Fuller states that instructors must be comfortable with one-to-one interaction with students rather than a traditional classroom setting where a classroom of 25 or more students are grouped as one body. He states that they must be flexible in their teaching approach and be willing to experiment (2000). The instructor should be as personable online as they would be in a traditional classroom. According to Kearsley and Blomeyer online instructors should be are friendly, pleasant, laid-back, helpful, available, possess a sense of humor and positive attitude, as well as a willingness to help (2004).

Rodriquez and Nash (2004), cited the work of Hagner and Schneebeck (2001) in developing four categories that faculty members can be classified under to illustrate their responses to creating and teaching online classes. These labels are the entrepreneurs, the risk aversives, the reward seekers, and the reluctants.

The entrepreneurs are those faculty members who meet the new model of teaching online directly and often lead the way in developing the online courses. Hagner and Schneebeck (2001) further suggest that these faculty members tend to have idiosyncratic techniques and work more productively in isolation, thereby suggesting that their methods are not accessible or useful to other faculty members (Rodriquez \& Nash, 2004).

The risk aversives are those faculty members, who are willing to create and teach online, but oftentimes are uncertain with the methods and lack technical expertise. This uncertainty can cause them to fear that their endeavors as an online instructor may fail. However, it may also encourage these faculty members to improve the quality of their teaching methods and learn more about the technology, which they see as a possible catalyst to improve their methods (Rodriquez \& Nash, 2004).

The reward seekers are those faculty members who do not support online teaching unless the administration changes the structure of their reward and recognition procedures to provide equitable compensation for the effort. If these faculty members perceive that accepting and implementing online teaching can further their careers, or be financially lucrative, then typically they will embrace it. In other words, if the faculty member receives something explicit in return for participation in the course development and teaching efforts in the online environment, they will accept the duty willingly (Rodriquez \& Nash, 2004). 
Finally, the reluctants are those faculty members who probably never will accept online teaching. Whether they fear the change itself, perceive a loss of power outside the classroom, or are apprehensive about the substantial workload that may be accomplished alone and possibly without sufficient training, they are unwilling to participate in the distance learning environment. Hagner and Schneebeck (2001) suggest that these faculty members typically are computer illiterate or believe that traditional classroom teaching is the best model to follow. Rodriquez and Nash (2004) support this claim by stating that it is the missing human element that enables these faculty members to respond in such a way.

\section{SUMMARY}

"Online education is neither right for all students nor right for all faculty..." (Kassop, 2003). While numerous studies address the need for a particular type of individual to teach in the virtual environment, and some even apply labels to various categories of instructors, there have been few attempts to develop an instrument which would evaluate an individual's propensity for instructing in the virtual environment. While no instrument can purport to measure an individual's success in the virtual environment with $100 \%$ accuracy, the need for a technique to offer an indication of an individual's potential success is apparent.

\section{PROBLEM STATEMENT}

The retention rate of students who elect to take courses through distance learning programs is lower than those who take traditional courses. Could the rising attrition rate be indicative of students who are not able to successfully learn the material in distance learning courses as a direct result of the teaching style of the instructor? This study attempted to determine if it is possible to predict whether an instructor is suited for distance learning courses by examining their teaching style. Specifically, the study attempted to determine, through the use of a teaching style inventory instrument, the individual styles of teaching which are better suited for the traditional classroom environment and those which would more likely prove successful in the distance learning environment. If it is indeed possible to determine that individuals with certain teaching styles perform better in distance learning courses than those with other styles, then administering a simple teaching style inventory instrument to perspective instructors would provide distance learning administrators with an indication as to whether an instructor should teach distance learning courses. This activity could increase the retention rate in that students would be taking classes with instructors whose teaching styles compliment the distance learning delivery method.

\section{SURVEY INSTRUMENT}

The instrument developed for this study sought to determine if it was possible to predict if an individual would be successful in the on-line delivery methodology by evaluating their perception of distance learning, and their preferred teaching style. The instrument was divided into two sections. The first section utilized a modified Likert instrument which asked individuals to respond to various statements by indicating either "Strongly Agree", "Agree", "No Opinion" "Disagree", and "Strongly Disagree". These statements asked individuals to evaluate various aspects of distance learning education along with issues related to student motivation.

The second portion of the study employed an author developed variation of the Kolb Learning Style Inventory (LSI) instrument to determine the preferred teaching style of the instructor. The Kolb Inventory is a selfdescriptive test, based on experiential learning theory, which is designed to assess the learner in the four stages of the learning process. According to the LSI there are four different learning modes: concrete experience (CE) in which students must be able to involve themselves fully and openly without bias in new experiences; reflective observation (RO) where students must be able to reflect on and observe experiences from many perspectives; abstract conceptualization (AC) in which students must be able to create concepts and integrate observations into logically sound theories; and active experimentation (AE) where students must be able to use theories to make decisions and solve problems (Osland, Kolb \& Rubin, 2001).

Similar to the LSI, the survey instrument measured an instructor's emphasis on the four learning modes by asking them to rank order a series of four words that describe the four different abilities. These words were assigned 
values relative to the relationships indicated in the Kolb study. Words which were more reflective of styles relating to traditional delivery systems were assigned a lower value index, while those which were determined to be an indication of receptiveness to on-line education received a higher value.

The five groups were selected from the Kolb model since they were reflective of the teaching experience, as opposed to the learning experience.

The score from this portion of the instrument was not combined with the Likert responses, but quantified separately in accordance with a methodology that was quasi reflective of the Kolb Learning Style Inventory. The authors perceived that keeping the results separate would be more beneficial in the research.

\section{RESULTS}

All instructors teaching for Embry-Riddle Aeronautical University's Extended Campus received an e-mail informing them about the survey, and asked them to go to the web address where the instrument was located and to complete it within a period of three weeks after receiving the e-mail. The instrument was posted for 21 days after the original e-mail was forwarded. The survey population consisted of the all instructors who teach for the Embry-Riddle Aeronautical University Extended Campus operation. At the end of the three week period, 200 responses to the instrument had been received.

\section{LIKERT QUESTIONS RESPONSES}

\section{Question 7. Students are motivated to perform academically.}

Over $74 \%$ of the responses "Agree" with this statement, with another $13 \%$ responding "Strongly Agree". The $11 \%$ who responded "Disagree" or "Strongly Disagree" have perceptions of student performance which would not appear to be consistent with teaching online. It would be more difficult to motivate students in a virtual environment as compared to being in the classroom.

\section{Question 8. Students require support groups to aid in the learning process.}

Over 50\% of the participants responded with Agree/Strongly Agree for this statement, while $44 \%$ stated Disagree/Strongly Disagree. While there are support groups available in the virtual environment, there are more opportunities in a traditional classroom to interact with students. Individuals who perceive the necessity for student support groups would probably be more comfortable knowing that they were readily available in the traditional environment.

\section{Question 9. More learning occurs outside the classroom than within.}

Approximately 46\% responded Agree/Strongly Agree, while 47\% responded Disagree/Strongly Disagree. While students do have the opportunity to communicate electronically, the opportunities are much more available in the traditional environment; as such an individual responding in the affirmative would appear to be more suited to the traditional classroom. Since the virtual classroom is more often viewed as education in the real world, traditional faculty might assume the application of concepts outside the classroom as the means to simulate the real world environment.

\section{Question 10. Having to log on to a computer and type in responses is a detriment to the learning process.}

The 13\% of those responding Agree/Strongly Agree to this statement would not appear to be receptive to the online environment. In today's high tech environment, one who would respond that having to log on to a computer is detrimental to the learning process would surely experience problems teaching in the online environment 


\section{Question 11. I enjoy teacher/student interaction.}

Over 99\% of the responses were Agree or Strongly Agree. Whether teaching in the traditional classroom or online, an individual who does not enjoy the interaction between student and instructor should probably not be in the classroom. This finding would support both the traditional and online classroom since interaction and rapport building is critical in both environments.

\section{Question 12. Interaction between student and teacher is necessary for learning to occur.}

While the majority of the respondents, over 80\%, responded Agree/Strongly Agree, the $20 \%$ who responded Disagree/Strongly Disagree may be more suited to the distance learning environment since the interaction is much more limited online, and it is possible for a student to post assignments and comments without ever interacting with the professor.

\section{Question 13. The more face-to-face interaction that occurs, the more learning that will occur.}

The 28\% who responded Disagree/Strongly Disagree express an opinion which is much more consistent with the virtual environment. They perceive that the need for face-to-face interaction is not a prerequisite for learning to take place. Faculty indicating that face-to-face interaction was not necessary for learning may perceive that students share the responsibility, and possibly the greater percentage of responsibility, for learning.

\section{Question 14. Students learn from being exposed to other students.}

Only $4 \%$ of the responses were either Strongly Disagree/Disagree. Clearly respondents believe the exposure to other students is a part of the learning experience. While there is a degree of exposure in the virtual environment, it is not at the same level of exposure as one would find in the traditional classroom. It is often possible for an online student to post assignments and comments without previewing the work or comments of classmates. The $4 \%$ could be construed to be conducive to virtual instruction.

\section{Question 15. Students taking classes on-line perform better than those in traditional classes.}

Approximately 58\% of those responding answered Disagree/Strongly Disagree to this statement, while 31\% had No Opinion or indicated a positive response. Those responding in the negative, believing that students in traditional classrooms perform better would not be well suited for the online environment. However, those who support the view that traditional classroom performance would be at the same level as their counterparts enrolled in online courses would be more likely effective in the virtual classroom.

\section{Question 16. The best instructors are those who assist in the learning process outside of the classroom.}

Approximately 58\% of the respondents stated Agree/Strongly Agree, compared to 22\% responding in the negative. While there can be interaction outside of a virtual classroom, the majority occurs within the class, utilizing the various components such as chat rooms, discussion boards, lockers, and digital dropboxes. The ability to provide outside assistance in the learning process is much more evident in a traditional setting since any activity provided beyond the classroom timeframe is considered outside assistance. Often there is little time to provide individual assistance in the classroom without detracting from the material to be covered. Those responding in the negative are more inclined to believe that learning outside the classroom is not necessary, and would be more comfortable in the online environment, believing that all student needs can be met in the self-contained classroom.

Question 17. There is no difference in the quality of online Power Point presentations as compared to those presented in traditional classes.

The $57 \%$ responding in the negative, as compared to the $27 \%$ affirmative, would indicate that instructors do not believe the quality of power points submitted by online students were of the same quality as their counterparts in the traditional classroom. Since the question only pertained to the Power Point presentation, it is interesting that such a high number of respondents did not perceive the quality to be equal. Possibly the instructor believes that the traditional classroom exerts a degree of pressure on students to step up to a higher standard of presentation. The $44 \%$ 
of those responding Disagree/Strongly Disagree/No Opinion would be more apt to perceive the quality of the work accomplished by online students to be equal to those of traditional students.

\section{Question 18. Knowing students on a personal basis is not necessary for learning to occur.}

While 63\% responded Agree/Strongly Agree to the statement, 34\% responded in the negative. The 34\% reporting the importance of the need to know students on a personal basis for learning to occur would seem to be better suited for the traditional classroom where they can develop personal relationships with students. Although it is possible to become personal friends with students to a limited extent in an online environment, it is much more likely to occur in a traditionally delivered course.

\section{Question 19. Students perceive online courses to be easier than traditional courses.}

While 50\% Disagree or Strongly Disagree with this statement, 32\% responded in the affirmative. The student perception of the level of difficulty is often the result of previous experience, or vicarious learning associated with both online and traditional courses, where the workload was determined to be lighter and the subsequent grade was achieved more easily.

\section{Question 20. The best instructors strive to relate to students.}

Over 99\% of the respondents answered in the affirmative to this question. Whether the course is conducted online or in the traditional classroom, the need to attempt to relate to students was viewed as something the best instructors would strive to accomplish.

\section{KOLB LEARNING INVENTORY}

It was determined that the online learning environment attracts a unique approach to teaching. The specific faculty-student interaction necessitates the development of rapport without the traditional face-to-face interaction between professor and student. The faculty-student relationship depends upon the instructor's ability to present information in a clear, concise and organized manner. The traditional classroom environment allows faculty to adjust the intensity or focus on various material as the class progresses through the semester eliciting continuous nonverbal feedback to redirect the faculty efforts. The online classroom environment requires all material to be uploaded prior to the start of the class; therefore, the adjustment of material is not as easily accomplished. Online faculty who adjust material after the start of the course, often discover that it creates more confusion and frustration since students often print out earlier versions of the same material. The faculty member subsequently finds his or her workload increased as explanations continue to be requested by students seeking clarification of requirements. Often, faculty members teach courses from a preset template and any adjustments are restricted.

The student is introduced to the blueprint of the course and then directed to follow the course map to a successful end. The instructor consistently monitors and evaluates the student's behavior through observational skills. The online environment assesses the student's learning outcome through various evaluation criteria including online examinations, research, participation in threaded discussions and submission of various virtual assignments. The student must rely on his or her own self discipline and time management skills to initiate continuous effort in order to complete all coursework and independently prepare for exams, which often test massive amounts of information in a short period of time. Because of the nature of skills required to support the virtual arena, it was determined that online faculty who would be most receptive to the distance environment would demonstrate higher numbers in the Abstract Conceptualization category, followed by the Reflective Observation category. The Concrete Experience and Active Experimentation categories were determined to correlate to a more traditional view of the classroom environment. Kolb suggests that the difference between the Abstract Conceptualization and Concrete Experience scores reveals the person's preference for abstractness over concreteness, while the difference between the Active Experimentation and Reflective Observation scores reveals the emphasis on experimentation over reflection. Concrete Experience basically focuses on new experiences without bias, Reflective Observation drives the individual to observe and reflect on the experiences, Abstract Conceptualization releases an ability to integrate various concepts into usable theories and finally the Active Experimentation supports the application of the theories toward decisions and problem solving 
techniques. The online environment was determined to be more compatible with the Abstract Conceptualization, since the primary focus is on the integration of concepts into theories. The faculty member is unable to visually show or demonstrate concepts in a classroom, but must virtually upload and integrate these concepts so that the student can comprehend the connection with theory. Reflective Observation was determined to be the second most important category since distance learning faculty present the information, and are subsequently involved in reflective evaluation of the student responses provided in assignments, examinations and discussion board input. The reflective activity takes on a more vital role for the faculty because it becomes the primary activity to assess the student's real understanding of the course material. The subjective exam questions, as well as all of the specific feedback provided to the student, must be reflectively and carefully formulated since there is much less opportunity to exchange information until the comprehension is fine tuned. The continuous barrage of verbiage that can occur in a face-to-face encounter may be complemented by the surrounding nonverbal information that confirms or contradicts the message, thereby informing the faculty of the probability of student understanding of the intended message. The online arena does not include the nonverbal signals and therefore it is essential that the faculty reflectively formulate and scrutinize the messages to be sent. It is not blatantly obvious when the student does not comprehend the material being presented. Concrete Experience was determined to be least compatible with online faculty since the total involvement in new experiences and without bias suggested by the Kolb instrument is not easily accomplished online. Distance learning faculty are not able to implement all senses and strategies while instructing online. They do not have access to nonverbal feedback and therefore must rely on only those strategies that are conducive to independent student comprehension of material without the direct faculty contact. Faculty need to draw on their past experiences and knowledge which have developed an accurate sense of behavioral judgment over time. For example, the professor can make a statement and immediately view facial expressions that indicate a lack of understanding, leading him or her to rephrase the material in a more comprehensive manner. The identical information presented online may be received with confusion as well, but the faculty member will not be privy to the nonverbal information, and often the student to faculty time delay in receiving or reacting to the information, may not support an immediate and timely adjustment to comprehension

Similarly, distance learning faculty are not comfortably involved in Active Experimentation since the contact with students is very restricted and the use of hands on experiential activity is almost entirely eliminated, and at the very least it is not monitored as closely. Debriefing of activities, unlike the traditional classroom, is very cumbersome in an online mode.

The following table indicates the five sets of words that correspond to the respective category listed directly below in the same column. The numbers one through four were assigned to each of the categories based on the determination of its value in the online learning environment. The Abstract Conceptualization was assigned a value of 4 since it was considered to be the most compatible with the online learning environment. The Reflective Observation category received a value of three as it was determined that it was the second most important focus supporting online instruction. The Active Experimentation and Concrete Experience categories were assigned the value of two and one respectively, since it was determined that these were the least compatible for the distance environment and would be more useful in the traditional classroom (Figure 1).

Similar to the LSI, the instrument measures an instructor's emphasis on the four learning modes by asking them to rank order a series of four words that represent the four different abilities. These words were assigned values relative to the relationships indicated in the Kolb study. Words which were more reflective of styles relating to traditional delivery systems were assigned a lower value index, while those which were determined to be an indication of receptiveness to on-line education received a higher value. The total point value for the number of responses ranged from a maximum value of 20 to a minimum of 4 . 
Figure 1. Assigned values for learning modes.

\begin{tabular}{|c|c|c|c|c|}
\hline $1^{\text {st }}$ set & Feeling & Watching & Thinking & Doing \\
\hline $2^{\text {nd }}$ set & Intuitive & Productive & Logical & Questioning \\
\hline $3^{\text {rd }}$ set & Abstract & Concrete & Observing & Active \\
\hline $4^{\text {th }}$ set & Experiential & Observational & Conceptual & Experimental \\
\hline $5^{\text {th }}$ set & Intense & Reserved & Rational & Responsible \\
\hline Learning Modes & $\begin{array}{c}\text { CE =Concrete } \\
\text { Experience }\end{array}$ & $\begin{array}{c}\text { RO=Reflective } \\
\text { Observation }\end{array}$ & $\begin{array}{c}\text { AC=Abstract } \\
\text { Conceptualization }\end{array}$ & $\begin{array}{c}\text { AE=Active } \\
\text { Experimentation }\end{array}$ \\
\hline Assigned Values & 1 & 3 & 4 & 2 \\
\hline
\end{tabular}

Based on the model derived from the Kolb Learning Inventory, the greater the score, the more the individual would appear to be suited for online instruction, while the lower the score, the more the individual would excel in the traditional mode. Of the 200 surveys received, only 154 were quantified due to completion errors in 46 of the surveys. Most of the errors were ones of omission, where a participant failed to provide an input for a set of terms, while others were due to the individual using the same values for different words in a set, thus making the data set unquantifiable. The mean for the responses to the 154 surveys was 12.76 , with a standard deviation of 2.88 . As mentioned previously, the higher the value, the more likely an individual would do well in an online environment. Based on these results and individual scoring in excess of one standard deviation from the mean, a raw score of approximately 15 appears to be very well suited for the virtual environment. The majority of those with scores between 12 and 15 should also expect to do well in a distance learning environment. Based on the results of this study, individuals with values less than 12, especially those with values 10 or below, may not find their teaching style to be compatible with the online learning environment. While the instrument does not purport to measure an individual's learning style with $100 \%$ accuracy, it presents an indication of how an individual perceives themselves as an instructor in reference to on-line education.

\section{REFERENCES}

1. Berge, Z.L. (1995). The Role of the Online Instructor/Facilitator. Retrieved March 14, 2004 from http/www.emoderators.com/moderators/teach_online.html.Bricken, M. (1991, July). Virtual Reality Learning Environments: Potential and Challenges. Computer Graphics. SIGGRAPH 91 Vol. 25. New York, NY: ACM.

2. Fuller, D. (2000). Internet Teaching by Style: Profiling the On-line Professor. Educational Technology \& Society, Vol. 3 (2)

3. Hagner, P.R., \& Schneebeck, C.A. (2001) Engaging the Faculty in Technology-enhanced Teaching and Learning, EDUCAUSE Leadership Strategies, C. Barone and P. Hagner, eds. Jossey-Bass, San Francisco, Vol 5. pp. 1-12.

4. Kearsley, G. \& Blomeyer, R. (2004, January/February). Preparing teachers to teach online. Educational Technology 44(1), 49-52

5. Osland, J., Kolb, D., \& Rubin, I (2001). Organizational behavior: An experiential Approach. Prentice Hall, Upper Saddle River, NJ

6. Reingold, H. (1998). The Virtual Community. Retrieved May 11, 2005 from http://www.rheingold.com/vc/book/

7. Rodriquez, F., \& Nash, S. (2004). Technology and the adult degree program: The human development. New Directions for Adult and Continuing Education, 103, 73-79.

8. Sherry, L. (1996). Issues in Distance learning. International Journal of Educational Telecommunications, 1 (4), 337-365. 